THE

TREATMENT OF BRONCHO-PNEUMONIA IN CHILDREN BY APPLICATION OF ICE.

BY ANGEL MONEY, M.D., M.R.C.P., aSSISTAYT PHYSICIAN TO UNIVERSITY COLLEGE HOSPITAL, AND TO THE HOSPITAT FOR SICK CHILDREN.

HAVING now treated many cases of severe broncho-pneumonia in children and infants by means of ice-bags, it seems desirable, owing to the success attending such treatment to urge the profession to consider its more general adoption. The cause of the broncho-pneumonia does not, in my experience, influence the employment of the ice-bag. It may be used with much success even in cases of broncho-pneumonia secondary to tracheotomy, but still more favourably in cases of influenza and measles. The smaller the child the more marked are its effects. In very small infants under one year of age the ice-bag may be placed on the head, the hair having previously beon thinned and shortened if necessary. The treatment to be successful must be carried out with a will and systematically. As a general rule, the rectal temperature affords the best guide to the application of cold, and those acquainted with broncho-pneumonia well know the highly marked remittent or almost intermittent character of these affections. Icebags have the drawback that they often give rise to a little wetting of the child, but this has not, in my experience, proved injurious to the patient. Leiter's tubes have been tried, and have some advantages, being especially valuable when an intelligent nurse is in attendance. The condensation of moisture caused by the cold is of course inevitable, but this wetting may be rendered harmless by covering the ice-bag or Leiter's tubing with a layer of Hartmann's wood wool or the compressed moss sphagnum. In severe cases, where a rapid effect is required, two icebags have been placed on the head, and one over the chief seat of consolidation in the lungs. With a little management it is not difficult to keep these in place; certainly not when the neuro-muscular prostration is marked, as it almost al ways is in eevere cases. The chief merits of this treatment consist in the maintenance of the strength, not only of the heart, but also of the respiratory centres and of the nervous and muscular systems. Although otitis media occasionally occurred, yet this has not been more frequent than in cases treated without cold. Albuminuria is not rendered worse by the cold, nor have any cases of hæmaturia been observed. The urine has, at some trouble, been specially collected and tested in small infants. The duration of the disease is, on the whole, shortened. Convalescence is almost invariably xendered more rapid, doubtless because of the conservation of the child's energy.

It is superfluous to assert that ice does not merely act by staaling heat; its action is almost exclusively sedative. Physiologists would aver that it increased inhibition, and in that way made wrong right; because disease simply lowers resistance in the vital processes, and curative measures raise it. Ice influences different organs differently, and this is most noticeable in the various parts of the nervous system. Its action on the cortex of the brain is, perhaps, most evident in the production of sleep, restless movements rapidly subsiding if the cold be efficiently applied; probably, therefore, the whole system of motor centres and sensory centres is soothed, because morbid sensations and morbid motions tend to cease. On the heart and circulation the influence is also decided, but this influence is probably exercised directly and indirectly; for not only does the cold directly quiet the beart and steady the circulation, but the calming of the nervous system also acts indirectly in the same direction. The respiratory centres are similarly beneficially affected. The heat-regulating apparatus manifests most clearly the same beneficent action, and the temperature chart shows a similar harmonious effect. It is curious to observe the almost immediate cooling of the whole surface of the body soon after the application of ice to any part, this cooling affect being perbaps best marked when the ice is applied to the head; the hands, previously red and hot, become cool and slightly blue. The change is decidedly favourable, notwithstanding the supervention of the signs of feeble circulation in the exposed parts of the skin. Vomiting and diarrhoea, alone or in combination, may require treatment in the cases under consideration; the cold method does not increase diarrhoa, and it certainly tends to stave off vomiting. The employment of cold does not obviate the necessity of using stimulante, either of the ordinary sort or such as act more especially on the heart and respiration. But cold renders them less necessary, and when they are required smaller doses are sufficient. There is, indeed, a saving of expenditure all round: the cost of the illness is lessened, and the illness costs the child less expenditure of reserve strength.

\section{SHOT EMBEDDED IN THE ORBIT FOURTEEN} YEARS ; ARACHNITIS.

BY E. WILLMER PHILLIPS, M.R.C.S., L.R.C.P.

THw following case presents a few points of medico-legal and clinical interest worthy of record.

E. A- , aged nineteen, an orphan, apprentice to a shoemaker, with whom he lived, had always been idle and rather childish. He often complained of headache, for which he attended at the hospital once; he was otherwise healthy. When five years old his right eye was removed at the German Hospital for gunshot injury caused by his uncle. His father died of consumption ; cause of mother's death unknown; one sister and two younger brothers living. On Nov. 9th, 1887, he went away without saying where he was going, previously having destroyed all letters, \&c., and he returned on the $14 \mathrm{th}$, refusing to say where he had been, but he seems to have had a bad cold in the head at the time. Heremained apparently well till the evening of the $24 \mathrm{th}$, when he refused to play with other boys. On the morning of the 25 th he got up complaining of headache, ate his breakfast, but subsequently had a rigor and vomited; he then went to bed and slept. His master noticed that ho was sleeping at night, and that he snored loudly. Next morning (the 26th) he could not be roused. When visited at 2 P.M. the patient was lying on his back unconscious; face very flushed; legs and thighs flexed; hands lying on the abdomen, which was retracted. He could not be made to protrude his tongue or swallow. His teeth were covered with sordes. He struggled with his hands when the abdomen was examined, as in cases of concussion. Temperature 101. $8^{\circ}$ pulse 120, regular; respiration about 20, irregular, long periods of rest, then sighing. No abnormal physical signs in the chest. Had passed urine in the bed. No tache cérébrale; no abdominal reflexes, knee jerk, or ankle clonus. No history or sign of blow or any injury or contagious disease. No discharge from ears. The right eye had been removed; no discharge between the lids.-9 P.M.: Temperature $103^{\circ}$. Keeps his head turned to the right; frequently kicks his legs out and moves his right arm, but he seldom moves his left. Cannot be made to swallow. Still unconscious. Left platysma contracts occasionally. Cold sponging and nutrient enemata ordered. Head to be shaved and ice-bag applied.

27th.-1 P.M.: Temperature $104^{\circ}$; pulse 145, small; respiration 20, irregular, sighing. No expression on right side of face; muscles on left side twitch; zygomatic muscles contract on being irritated. Can close left eye. Wrinkles on left forehead very marked, but not on right. Face much paler. Patient does not move the left arm much, but is able to do so; frequently moves both legs and right arm. No abdominal or other reflexes. -5 P.M. : Temperature $104^{\circ}$. Slight rigidity of right arm; fingers kept flexed; subsultus and jerky flexion of wrist. Membrana tympani examined, and apparently healthy.-11 P.M. : Temperature $104 \cdot 6^{\circ}$; pulse small, uncountable; respiration 24. Lower limbs rather rigid; plantar reflexes present. Hands and feet cold. Muscles on left side of face contract when the skin is touched with ice, but not on right side. Head slightly retracted and neck rigid. Left optic disc clear and normal.

28th.- The patient died at 19.15 A.M. from increasing coma. There were no convulsions. Rigor mortis commenced at 9.40 A.M.

Necropsy, twenty-nine hours after death--Rigor mortis present. No external signs of injury. Calvaria healthy. Membranes of brain apparently congested. Small patch of pus on visceral arachnoid over right frontal lobe, also on its 
under surface. On removing the brain, the crura cerebri were so soft that they readily tore asunder in front of the pons. No tubercle on membranes. Pus present over pons and medulla. The brain appeared healthy on section. Very little fluid in lateral ventricles. Pus was present over the right olfactory foramina, and could be traced through a small opening into the inner angle of the orbit about the junction of the lacrymal and frontal bones. On removing the roof of the right orbit and opening the frontal sinuses, these were found to contain thin but not foul pus, which extended towards the nasal duct. The anterior portion of the superior oblique muscle was softened and infiltrated with pus, also the cellular tissue in its neighbourhood. Close to this was a small mass of shot (seven in number); there was also one embedded in the upper part of the lacrymal bone. Beneath the skin over the nasal process of the right superior maxillary bone were three shot, and beneath the lower eyelid were three more (some of these were noticeable during life). There was also a mass of shot (115) extending from the ephenoidal fissure along the outer border of the rectus externus to the outer angle of the orbit; there was not any pus in this part. All the shot (129) were apparently encapsuled; none could be found loose. The right ethmoidal and sphenoidal sinuses were filled with thin pus, the lining membrane being thickened and exsily peeling off. The whole of the right superior maxillary and nasal bones were removed; the mucous membrane covering the middle and inferior turbinated bones was slightly congested, but no ulcer, dead bone, or shot could be found. No thrombosis of sinuses $\mathrm{nr}$ fracture of skull could be detected. Other organs healthy.

\section{ON THE}

\section{VALUE OF SALOL IN THE TREATMENT OF ACUTE RHEUMATISM.}

BY J. ROSE BRADFORD, B.Sc, M.R.C.S., LATE HOUSE PHYSICIAN, UNIVERSITY COLLEGE HOSPITAL.

DURING my tenure of the post of house physician to Dr. Ringer I had an opportunity of testing the value of salol in some sixteen cases of theumatic fever admitted under his care. Inasmuch as the drug is still on its trial, it was thought worth while to publish a short account of the results obtained.

Salol, as is well known, is a compound of salicylic acid and phenyl, and, according to the analyses of Tate, the ordinary commercial salol contains about 36 per cent. of phenyl. Hence the question arises as to whether its action as an antirheumatic is simply due to the salicylic acid it contains, or whether salol possesses other properties which make it superior to salicylate of soda. At the present time different observers are not agreed, since according to several it is stated to be superior to salicylate of soda. Others, however, consider that the only advantages of the use of salol are that its taste is not so unpleasant, and that its use is not so liable to be followed by toxic effects as so frequently occurs with salicylate of soda. Before discussing the results obtained, it will be convenient to give a short summary of a few amongst the sixteen cases treated. They were all of average severity. In most cases the temperature on admission was between $102^{\circ}$ and $103^{\circ}$, some, however, being as low as $1012^{\circ}$. The sixteen cases consisted of three young adults, five children (ages varying from eight to thirteen years), and eight women (ages varying from seventeen to forty-eight years). In two cases pericarditis and endocarditis resulted. These patients-a boy aged thirteen and a woman aged thirty respectivelyleft the hospital with a mitral systolic murmur. In the former case the patient also developed erythema circinatum over the abdomen and legs, and the female patient had an attack of hyperpyrexia, the temperature reaching $110.4^{\circ}$ before the pericarditis. In the remaining cases there were no complications. The following are examples of a few of the cases.

E. W- - a female aged twenty-six, general servant, was admitted into University College Hospital on Oct. 4th, 1887, compaining of headache and pains in the hips and knees. There was no previous history of rheumatic fever. On Sept. 30th the patient, had slight pain in the left knee. On Oct. 3rd she had pain in the other knee and in both hips, and she took to her bed. Temperature on admission $101 \cdot 6^{\circ}$; pulse 130 ; respiration 24 . Both wrist joints were found to be swollen, but only slightly painful on movement. There was no pain in the elbows, shoulders, or ankles. Left knee acutely painful and considerably distended. Patella floating, and this markedly better than on the right side, which, however, was also painful on movement. At 7 P.M. the temperature had risen to $102.8^{\circ}$, and the woman was ordered ten grains of aalol every two hours. During the night the temperature fell steadily, reaching $1008^{\circ}$ at 11 A.M. on Uct. 5th. On the 6th the temperature fell to $100^{\circ}$, and on the 7 th to $99^{\circ}$. The patient, however, vomited three times on the $6 \mathrm{th}$ after her medicine, but this was obviated by giving the salol in soda-water. With the lowering of temperature the pulse fell from 136 on the 4 th to 72 on the 7 th. The pain diminished in intensity during the 5th and 6th, but she was not quite free from pain until the 7 th. On and after the 7 th the salol was given every four hours, and at no time during its administration was there any complaint of deafness or noises in the head.

S. H-, a female aged seventeen, servant, was admitted on Nov. 7tb, complaining of pain in the ankles and swelling of the feet. On Oct. 30th she first felt unwell, experiencing general aching pains in the back and limbs; this continued until Nov. 4th, when the pains "settled" in ber ankles. During the evening her ankles and feet began to swell, and the pain beeame worse. On the 5 th the pain and swelling had still further increased, and she began to sweat pro. fusely. On admission, al 3 P.M., both ankle joints wero found to be swollen, tender, and there was considerable œdema of the dorsum of the feet and of the front of the legs for some three inches above the ankle joints. Both knee joints were slightly swollen and rather painful. There was some pain in the wrist joints, but no swelling or tenderness. The temperature at 3 P.M. was $101^{\circ}$; at 7 P.M. it had risen to $103^{\circ}$; and at $11 \mathrm{~A}$ M. on Nov. 8th it was again $103^{\circ}$, having fallen to $102^{\circ}$ during the night. No medicine was given until $11 \mathrm{AM}$. on the $8 \mathrm{ch}$, the patient's joints having been smeared with glycerine and belladonna, and hot fomentations applied. At 11 A.M. ten grains of salol were ordered every hour; at 3 P.M. the temperature had fallen to $100^{\circ}$, and at 7 P.M. a further fall to $98.6^{\circ}$ had occurred. During the ensuing night salol was given every two hours, and the highest temperature on the $9 \mathrm{th}$ was $100^{\circ}$ 。 On increasing the dose to ten grains hourly, the temperature fell to $984^{\circ}$. Between the $9 \mathrm{ch}$ and 10th the temperature kept down. On the 15 th, however, it rose to $100^{\circ}$, and on the 16th to $101 \cdot 4^{\circ}$. The patient, however, had no pain anywhere, and the temperature fell on the 17 th to normal. She was discharged on Dec. 5th, having had a relapse on Nov. 21st, which lasted until the 24th. In this case the patient's pain was greatly relieved within twenty-four hours from the time of administration of the salol, and on Nov. 10th it had quite disappeared.

A. H-... a female aged thirty-two, housewife, was admitted at 3 P.M. on Oct. 13th, the eighth day of illness. The patient complained of considerable pain in the ankles, knees, hips, elbows, and shoulders; the ankles were, however, the only joints swollen. The temperature on admission was $101 \cdot 8^{\circ}$. Ten grains of salol were given every two hours, the first dose being given at 7 P.M. The temperature in the next twelve hours fell to $99.8^{\circ}$. On Oct. 14th it had reached $1002^{\circ}$ at $11 \mathrm{AM}$. The salol was then increased to ten grains every hour, the temperature falling in twelve hours to $99^{\circ}$. For the next forty-eight hours the salol was given hourly during the day, and every three hours at night, and the temperature did not rise above $99^{\circ}$. On the 16th the patient developed a mitral systolic murmur; and on the 25th she had a relapse, with pain in the knee and ankle joints, the temperature rising to $100 \cdot 4^{\circ}$, probably due to the fact that on the 24 th the salol was diminished to ten grains every three hours; this relapse, however, quickly yielded to increased doses, and the patient was discharged on Nov. 6th. In this patient the salol caused some nausea, headache, and deafness.

It is not necessary to detail any of the other cases, as they are essentially similar to the above; any slight differences that were noted will be mentioned below. It will be most convenient to discuss the results obtained in these and the other thirteen cases under the following four heads: (1) the rapidity of its action as an antipyretic: (2) its efficacy in relieving the joint pains; (3) the liability to relapses after or during its use; and (4) the production of toxic symptoms. 1. As an antipyretic, salol is decidedly efficacious in 